\title{
Pancreatic autoantibodies in Crohn's disease: a family study
}

\author{
F Seibold, H Mörk, S Tanza, A Müller, C Holzhüter, P Weber, M Scheurlen
}

\begin{abstract}
Background-Pancreatic antibodies occur in about one third of patients with Crohn's disease.

Aims-To evaluate the relevance of pancreatic antibodies as a genetic marker in patients with Crohn's disease and their first degree family members and spouses. To characterise further pancreatic antibodies by assessment of IgG subclasses. Methods-Six hundred and fifty serum samples were tested for pancreatic antibodies by immunofluorescence on sections of human pancreas. Incidence of pancreatic antibodies and their subtypes were studied on 212 serum samples from patients with Crohn's disease. In the familial study, 72 patients with Crohn's disease and 196 first degree family members and 26 patients with ulcerative colitis and 90 first degree family members were included. Ten healthy families served as controls.
\end{abstract}

Results-Pancreatic antibodies were found in $58(27 \%)$ of the patients with Crohn's disease and in none of the controls. Thirty patients had pancreatic antibodies of subtype I characterised by a drop-like fluorescence in the pancreatic acini, 28 patients had subtype II with a fine speckled staining in the acinar cells. Pancreatic antibodies of subtype $I$ were both IgG1 and IgG2 antibodies by contrast with subtype II which were mainly of IgG1 subclass. Only five of 196 first degree relatives of patients with Crohn's disease had pancreatic antibodies. Four of these people had anamnestic data compatible with inflammatory bowel disease. Further investigations showed Crohn's disease in two of these people. In families with more than one member positive for pancreatic antibodies, pancreatic antibodies were of the same subtype in all cases.

Conclusions-Pancreatic antibodies are a specific marker for Crohn's disease. Two subgroups of pancreatic antibodies can be distinguished by their pattern and immunoglobulin subclasses. Pancreatic antibodies rarely occur in family members of patients with Crohn's disease. These family members may also have Crohn's disease.

(Gut 1997; 40: 481-484)

Keywords: Crohn's disease, family study, pancreatic antibodies.

The aetiology of Crohn's disease has not yet been resolved. Data suggest that immuno- logical and genetic factors play a major part. The incidence of inflammatory bowel disease is increased in families of patients with inflammatory bowel disease. ${ }^{1-4}$ Occurrence of Crohn's disease is increased among relatives of patients with the disease, the percentage with a positive family history ranges between $8 \%$ and $39 \% .^{5}$ The risk of inflammatory bowel disease in first degree relatives of patients differs in different populations. For example, it is increased in the Jewish population. ${ }^{7}$ One of the current hypotheses of the pathogenesis of inflammatory bowel disease favours an inappropriate immune response to luminal antigens, especially to bacteria, leading to chronic inflammation in the intestinal tract. ${ }^{8} \mathrm{~A}$ variety of autoantibodies have been described in inflammatory bowel disease. ${ }^{9}$ There is no evidence that any of these have pathogenetic relevance. Only a few of the autoantibodies are specific for Crohn's disease or ulcerative colitis. Autoantibodies often found in patients with ulcerative colitis $(70 \%)$ and in patients with primary sclerosing cholangitis $80 \%$ are primarily directed against neutrophils (pANCA). ${ }^{10-12}$ In Crohn's disease this autoantibody is found in 3-27\% of patients but only in low titres. ${ }^{10}$ pANCA was found not only in patients but in healthy relatives of patients with ulcerative colitis or primary sclerosing cholangitis. ${ }^{1314}$ By contrast with our own results, another group found pANCA in relatives at a significantly higher frequency in families of pANCA positive patients than in families of pANCA negative patients. ${ }^{13}$ Thus pANCA may be useful as a marker of genetic predisposition. There are only a few antibodies which occur specifically in Crohn's disease. Recent data show that antierythrocyte antibodies (AEA 15) occur at high frequency in Crohn's disease. ${ }^{15}$ Autoantibodies to pancreas (PAB) are characterised by a high disease specificity although the incidence in Crohn's disease is only $31 \% .{ }^{16}{ }^{17}$ Like pANCA, PAB were not influenced by the severity of disease - titres remained stable for several years. ${ }^{17}$ In this study we further characterised PAB and differentiated between two subtypes of PAB. The frequency of PAB in families of patients with Crohn's disease and ulcerative colitis was analysed to investigate the role of $\mathrm{PAB}$ as a genetic marker.

\section{Methods}

PATIENTS

Tests for PAB were carried out on 673 serum samples; 461 patients, relatives, and controls were included in the family study. Outpatients 
with inflammatory bowel disease were invited to participate. Serum samples from patients and their relatives were taken at their homes and stored at $-20^{\circ} \mathrm{C}$ until use. All relatives tested were questioned about a possible history of inflammatory bowel disease. Information collected included a history of diarrhoea, tenderness, abdominal pain, tenesma, body weight, fever, anaemia, growth retardation, and medical treatment. Further, all relatives were asked about possible extraintestinal manifestations such as skin diseases, arthralgia, arthritis, ocular inflammation, and fistulas. Diagnosis of Crohn's disease was established on endoscopical, histological, and clinical criteria according to the European Cooperative Crohn's disease study. ${ }^{18}$ The age of the 72 patients with Crohn's disease (32 women, 40 men) ranged between 18 and 69 years. One hundred and ninety six first degree relatives of patients with Crohn's disease were included.

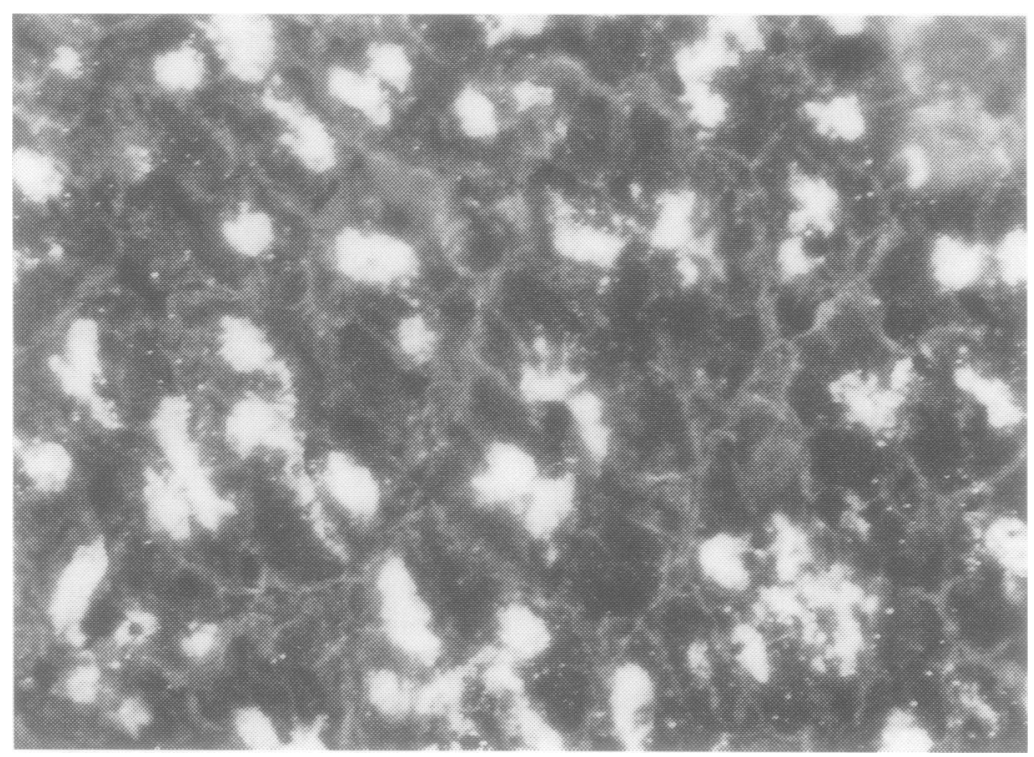

Figure 1: Typical fluorescence pattern of serum with PAB type I characterised by a drop-like staining within the pancreatic acini (original magnification $\times 500$ ).

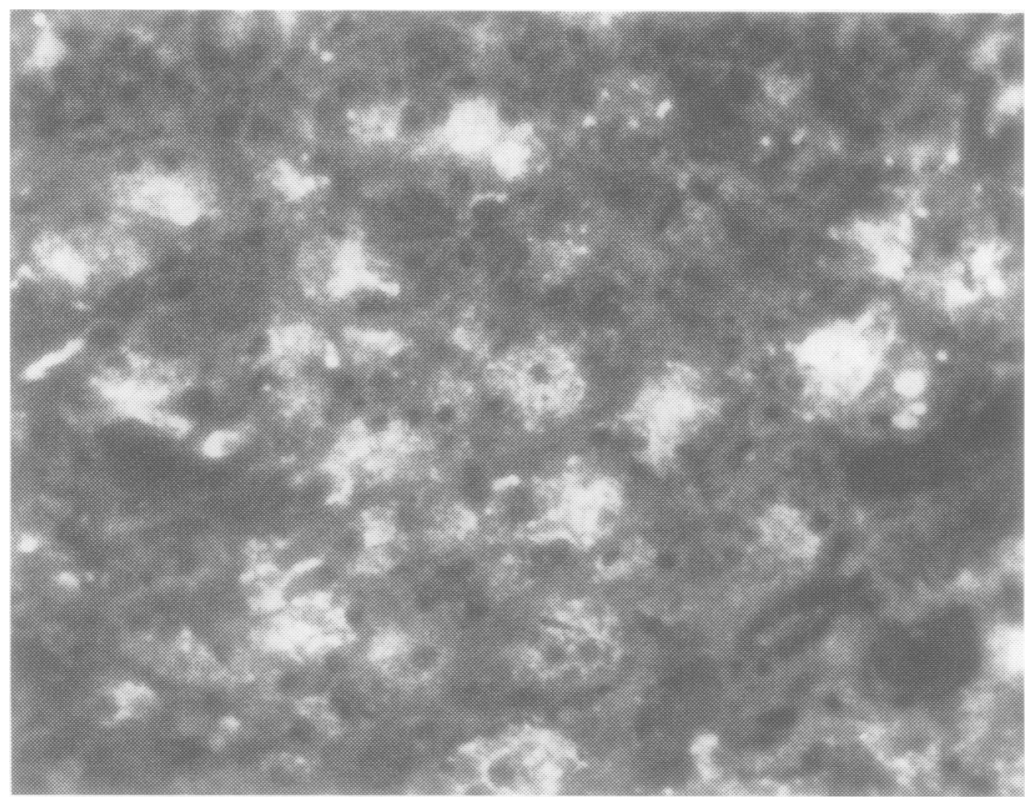

Figure 2: Fluorescence pattern of PAB II with fine speckled staining of the acinar cells (original magnification $\times 500$ ).
Seventy six of them were parents ( 44 women and 32 men), 31 were brothers, 30 were sisters, and 59 were children (32 daughters and 27 sons). We also evaluated serum samples from 26 spouses ( 14 women, 12 men) of patients with Crohn's disease and four second degree relatives (grandparents). One patient with Crohn's disease had concomitant primary sclerosing cholangitis, two patients had psoriasis, one idiopathic thrombopenic purpura, and one Bechterew's disease. Twenty six patients with ulcerative colitis and their 90 first degree relatives and 10 healthy persons and their 37 first degree relatives were tested as controls. Diagnosis of ulcerative colitis was established by the criteria of Truelove and Witts. ${ }^{19}$ The age of these subjects ranged from 21 to 63 years. For assessment of the prevalence of $\mathrm{PAB}$ and their subtypes 212 serum samples from outpatients with Crohn's disease were investigated.

INDIRECT IMMUNOFLUORESCENCE TEST Sections of human pancreas (blood group $\mathrm{O}$ ) were used for detection of PAB. The sections were incubated for 40 minutes in a moist chamber at $20^{\circ} \mathrm{C}$ with $50 \mu \mathrm{l}$ serum samples (diluted 1:10 in phosphate buffered saline (PBS)). After washing with PBS, sections were incubated with polyvalent fluorescein conjugated sheep antihuman immunoglobulin (Dako, diluted 1:25 in PBS) for 30 minutes. After washing the sections were embedded in Immuno-Mount (Shandon) and read in a Leitz fluorescence microscope. All slides were coded for anonymity and read independently by two investigators. Determination of IgG subclass was done as described above using IgG1, IgG2, IgG3, IgG4, IgA, and $\operatorname{IgM}$ as antihuman immunoglobulins (Sigma, Dako).

\section{Results}

PREVALENCE AND SUBTYPES OF PAB IN PATIENTS AND CONTROLS

Pancreatic antibodies were found in $58(27 \%)$ of 212 unselected patients with Crohn's disease. Two types of PAB could be distinguished. PAB I were characterised by a droplike staining in the lumen of pancreatic acini, whereas PAB II showed a fine speckled staining of the acinar cells. In almost all PAB type II a weak type I fluorescence was found as well (Figs 1 and 2). Thirty patients were positive for PAB I, and 28 patients were PAB II positive. Titres ranged from 1:20 to 1: 320 (Fig 3). In the family study 34 PAB positive patients were included. Fourteen patients were positive for PAB I, and 20 patients for PAB II. The antibody was not found in any of the patients with ulcerative colitis or the controls.

IMMUNOGLOBULIN AND I g G SUBCLASSES OF PAB I AND PAB II

PAB I and II were IgG antibodies. In $48 \%$ IgA and in $8 \% \operatorname{IgM}$ were also found. Determination of IgG subclasses showed that 


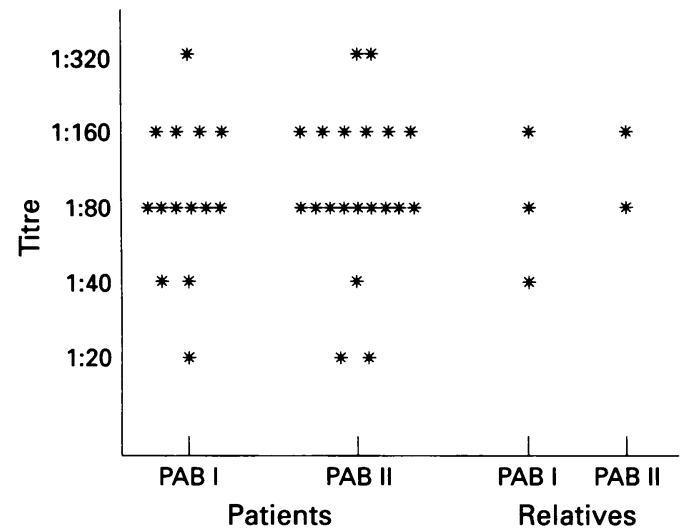

Figure 3: Titres of pancreatic autoantibodies type I and II (PAB I and II) in patients with Crohn's disease and their relatives.

the type II fluorescence was due to IgG1 antibodies, whereas the type I fluorescence was caused by IgG1 and IgG2 antibodies (Table I).

PREVALENCE OF PAB IN FIRST DEGREE

RELATIVES AND SPOUSES

PAB were detected in five of the 196 relatives of patients with Crohn's disease. PAB I were found in three members, and PAB II in two members. It was not found in the control families of healthy persons or patients with ulcerative colitis (Table II). Three PAB positive relatives had a $P A B$ positive patient in their family, whereas the remaining two $P A B$ positive relatives had $\mathrm{PAB}$ negative patients in

TABLE I Immunoglobulin subclasses of PAB I and II

\begin{tabular}{llllllll}
\hline & $n$ & $I g G 1$ & $I g G 2$ & $I g G 3$ & $I g G 4$ & $I g A$ & $I g M$ \\
\hline PAB I & 30 & $30(100 \%)$ & $20(66 \%)$ & $1(3 \%)$ & $1(3 \%)$ & $16(53 \%)$ & $2(6 \%)$ \\
PAB II & 28 & $28(100 \%)$ & $7(25 \%)$ & 0 & $2(7 \%)$ & $12(35 \%)$ & $2(7 \%)$ \\
\hline
\end{tabular}

TABLE II Prevalence of PAB in patients with Crohn's disease, ulcerative colitis, and their first degree family members and healthy persons

\begin{tabular}{lllllll}
\hline & $\begin{array}{l}\text { Patients } \\
n\end{array}$ & $\begin{array}{l}\text { PABI } \\
n\end{array}$ & $\begin{array}{l}\text { PABII } \\
n\end{array}$ & $\begin{array}{l}\text { Relatives } \\
n\end{array}$ & $\begin{array}{l}\text { PABI } \\
n\end{array}$ & $\begin{array}{l}\text { PAB II } \\
n\end{array}$ \\
\hline Crohn's disease & 72 & 14 & 20 & 196 & 3 & 2 \\
Ulcerative colitis & 26 & 0 & 0 & 90 & 0 & 0 \\
Controls & 10 & 0 & 0 & 37 & 0 & 0 \\
\hline
\end{tabular}

TABLE III Comparison of PAB status and clinical symptoms of relatives of $P A B$ positive and $P A B$ negative patients

\begin{tabular}{|c|c|c|c|c|}
\hline & \multicolumn{2}{|c|}{$P A B$ negative patients $(n=38)$} & \multicolumn{2}{|c|}{$P A B$ positive patients $(n=34)$} \\
\hline & $\begin{array}{l}P A B \text { negative } \\
\text { relatives }\end{array}$ & $\begin{array}{l}P A B \text { positive } \\
\text { relatives }\end{array}$ & $\begin{array}{l}\text { PAB negative } \\
\text { relatives }\end{array}$ & $\begin{array}{l}P A B \text { positive } \\
\text { relatives }\end{array}$ \\
\hline Asymptomatic relatives & 80 & 0 & 88 & 1 ? \\
\hline Symptomatic relatives & 12 & 2 & 11 & 2 \\
\hline Undiagnosed & 7 & $\overline{1}$ & 8 & 1 \\
\hline Crohn's disease & 2 & i & 2 & 1 \\
\hline Ulcerative colitis & 3 & 0 & $\overline{1}$ & 0 \\
\hline \multicolumn{5}{|l|}{ Symptoms: } \\
\hline Frequent diarrhoea & 10 & 2 & 10 & 2 \\
\hline Abdominal pain & 8 & 2 & 6 & 1 \\
\hline Fistula & 2 & 0 & 1 & 1 \\
\hline Aphtous disease & 4 & 1 & 3 & 1 \\
\hline Arthritis & 2 & 2 & 1 & 0 \\
\hline
\end{tabular}

their family (Table III). The three PAB positive relatives had the same PAB subtype as their diseased PAB positive family members. None of the 26 spouses were positive. Four families with two patients each with Crohn's disease were included in this study. In one of the families PAB were detectable in both patients, in two families only one person was positive for $\mathrm{PAB}$, and one family was completely negative for PAB. In one family there were five patients with inflammatory bowel disease (three with Crohn's disease, two with ulcerative colitis). None of the family members was positive for PAB. Because we compared the relatives of the PAB positive patients with those of the PAB negative patients, we also compared the mean age of both groups of relatives to exclude bias. The relatives of the PAB positive patients comprised 40 parents, 32 brothers and sisters, and 27 children; mean age 39.51 years. The relatives of PAB negative patients comprised 36 parents, 29 brothers and sisters, and 32 children; mean $39 \cdot 26$ years.

CORRELATION OF PAB WITH CLINICAL DATA

Four of the five first degree relatives positive for PAB had clinical symptoms compatible with inflammatory bowel disease (Table III). One patient did not complain of any symptoms. Crohn's disease was diagnosed in two of the PAB positive relatives. The other three have refused diagnostic investigation so far.

\section{Discussion}

Several studies have described familial Crohn's disease. ${ }^{2-4}$ Genetic factors play an important part in the pathogenesis of inflammatory bowel disease. HLA class I and II and several autoantibodies have been investigated in inflammatory bowel disease in the search for genetic markers. The characteristics of a good genetic marker are constancy, a high specificity, and familial nature. PAB were found to be very specific for Crohn's disease. Previously, we tested 471 serum samples of patients with various diseases (autoimmune diseases, coeliac disease, Crohn's disease, ulcerative colitis, colon cancer, and pancreatitis) for PAB and found them in $31 \%$ of the patients with Crohn's disease, in $4 \%$ of patients with ulcerative colitis, but in none of the others. ${ }^{17}$ The frequency and specificity of PAB found in this study are comparable with previous studies. ${ }^{1617}$ Titres of PAB were constant over a period of 18 months. ${ }^{17}$ The occurrence of PAB did not correlate with disease activity, extent of disease, extraintestinal manifestations, or fistular disease. ${ }^{17}$ Because of the characteristics of PAB we investigated the occurrence of PAB in family members of patients with inflammatory bowel disease. PAB were found in only five of the first degree relatives. Anamnestic data, however, suggested that these members had undiagnosed Crohn's disease. Indeed, the diagnosis of Crohn's disease has been etablished in two of the five members so far. Therefore, the presence of PAB is a marker for Crohn's disease, but by contrast with pANCA it seems 
not to be found in unaffected family members Determination of PAB may be helpful in detecting patients with mild or early Crohn's disease. These data contrast with the findings for pANCA, which is an autoantibody with a high specificity and frequency in patients with ulcerative colitis. In an English study, no pANCA could be detected in family members, ${ }^{18}$ but American and German studies found pANCA in about one third of the first degree family members. ${ }^{13} 14$ The results of the second two studies indicated that pANCA may have a role as a genetic marker.

We investigated 72 families of patients with Crohn's disease. In seven of them we found at least two cases of inflammatory bowel disease. Adding the families of the three persons who were positive for $\mathrm{PAB}$ but refused further diagnostic investigation there was a $14 \%$ positive family history in our patient group, which is comparable with other studies. ${ }^{2-4}$ Morphological analysis disclosed two different PAB staining patterns on pancreatic sections. Both types were specific for Crohn's disease. The antigen reacting with PAB is not yet known. As we reported previously the antigen is localised in the pancreatic secretion and is a macromolecule. ${ }^{17}$ The different IgG subclass distribution of PAB I versus II may show different types of immune response. The PAB subtype of the family members was the same within one family. The development of antibodies in inflammatory bowel disease is probably an epiphenomenon which might be caused by cross reactivity with other antigens for instance, of bacterial origin. The dysregulated immune response leading to this phenomenon is probably genetically determined. Therefore, it is not surprising that members of one family had the same PAB subtype. Environmental factors leading to the expression of PAB can be excluded as PAB were not found in any of the spouses.

In conclusion, PAB are a specific marker for Crohn's disease. This antibody may be helpful in the diagnosis of Crohn's disease.
1 Lewkonia RM, Mc Connell RB. Familial prevalence of inflammatory bowel disease - hereditary or environment? Gut 1976; 17: 235.

2 Mayberry JF, Rhodes J, Newcombe RG. Familial prevalence of inflammatory bowel disease in relatives of patients with Crohn's disease. $B M \mathcal{F} 1980 ; \mathbf{2 8 0}: 84$.

3 Orholm M, Munkholm P, Langholz E, et al. Familial occurrence of inflammatory bowel disease. N Engl $f$ Med occurrence of inflan

4 Monsén U, Berell O, Johansson C, Hellers G. Prevalence of inflammatory bowel disease among relatives of patient with Crohn's disease. Scand f Gastroenterol 1991; 26: 302.

5 Weterman IT, Peña AS. Familial incidence of Crohn's disease in the Netherlands and a review of the literature Gastroenterology 1984; 86: 449 .

6 Farmer RG. Study of family history among patients with inflammatory bowel disease. Scand f Gastroenterol 1989; 24 (suppl): 64.

7 Yang H, McElree C, Roth M-P, et al. Familial empiric risk for inflammatory bowel disease. Differences between Jews and Non Jews. Gut 1993; 34: 517-24.

8 Elson CO. Experimental models of IBD: lessons from mice. In: Tytgat GNJ, ed. Inflammatory bowel disease. DorIn: Tytgat GN], ed. Inflammatory bowel disease. Dor-

9 Seibold F, Weber P, Scheurlen M. Autoantibodies in IBD patients and their families. In: Tytgat GNJ, ed. Inflammatory bowel disease, Dordrecht: Kluwer Academic Publishers, 1995: 239-43.

10 Seibold F, Weber P, Klein R, Berg PA, Wiedmann KH Clinical significance of antibodies against neutrophils in patients with inflammatory bowel disease and primary sclerosing cholangitis. Gut 1992; 33: 657-62.

11 Saxon A, Shanahan F, Landers C, Ganz T, Targan S. A subset of antineutrophil anticytoplasmic antibodies is associated with inflammatory bowel disease. $f$ Allergy Clin Immunol 1990; 86: 202-10.

12 Rump AJ, Schoelmerich J, Gross V, et al. A new type of perinuclear anti-neutrophil cytoplasmic antibody of perinuclear anti-neutrophil cytoplasmic antibody (pANCA) in active ulcerative colitis but

13 Shanahan F, Duerr R, Rotter JI, et al. Neutrophil autoantibodies in ulcerative colitis: familial aggregation and genetic heterogeneity. Gastroenterology 1992; 103 456-61.

14 Seibold F, Slametschka D, Gregor M, Weber P. Neutrophil autoantibodies: a genetic marker in primary sclerosin cholangitis and ulcerative colitis. Gastroenterology 1994; 107: $532-6$

15 Berberian LS, Valles Ayoub Y, Gordon LK, Targan SR, Braun J. Expression of a novel autoantibody defined by the VH3-15 gene in inflammatory bowel disease and Campylobacter jejuni enterocolitis. F Immunol 1994; 153. 3756-63.

16 Stöcker W, Otte $M$, Ulrich S, et al. Autoimmunity to pancreatic juice in Crohn's disease. Scand $\mathcal{F}$ Gastroenterol pancreatic juice in Croh

17 Seibold F, Weber P, Jenss H, Wiedmann KH. Antibodies to a trypsin sensitive pancreatic antigen in chronic inflammatory bowel disease: specific markers for subgroup of patients with Crohn's disease. Gut 1991; 32 1192-97.

18 Malchow H, Ewe K, Brandes JW. European cooperative Crohn's disease study (ECCDS): results of drug treatment. Gastroenterology 1984; 86: 249-66.

19 Truelove SC, Witts LJ. Cortisone in ulcerative colitis: final report of a therapeutic trial. $B M \mathcal{F} 1955$; ii: $1041-8$.

20 Lee CW, Lennard-Jones JE, Cambridge G. Antineutrophil antibodies in familial inflammatory bowel disease. Gastroenterology, 1995; 108: 428-33. 